\title{
Area Under Curve UV Spectrophotometric Method for Determination of an Opioid Analgesic in Bulk
}

\author{
Snehal G. Gandhat *, Shankar M. Dhoble, Vrushali B. Kakade \\ Vishal Institute of Pharmaceutical Education and Research Ale, Tal-Junnar, Dist-Pune (412411) Maharashtra, India
}

\begin{abstract}
The aim of this work is to establish rapid, simple, precise and economical methods viz., area under curve were developed and validated for estimation of tramadol hydrochloride in pharmaceutical dosage forms. Further, this study is designed to validate the developed methods as per ICH guidelines. The work was carried out to for estimation of Tramadol in bulk pharmaceutical form by utilizing area under curve (AUC) method using UV-Visible Spectrophotometry. For this purpose the wavelength range 200-400 nm was selected. Distilled water was used as a solvent throughout the work. Linearity was observed in concentration range $5-25 \mu \mathrm{m} / \mathrm{ml}\left(\mathrm{r}^{2}=0.9992\right)$ for the method. The developed method was found to be simple, linear, precise, accurate and sensitive which can be used for routine quality control analysis for spectrophotometric estimation of Active Pharmaceutical Ingredient.
\end{abstract}

Keywords: Tramadol HCL, Distilled water

Article Info: Received 24 March 2019; $\quad$ Review Completed 25 April 2019; $\quad$ Accepted 01 May 2019; Available online 15 May 2019

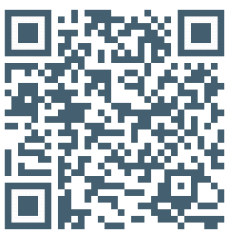

Cite this article as:

Gandhat SG, Dhoble SM., Kakade VB, Area Under Curve UV Spectrophotometric Method for Determination of an Opioid Analgesic in Bulk, Journal of Drug Delivery and Therapeutics. 2019; 9(3):151-153

http://dx.doi.org/10.22270/jddt.v9i3.2629

Ms. Snehal Govind Gandhat, Department of M.Q.A, Vishal Institute of Pharmaceutical Education and Research, Ale, Tal-Junnar, Dist-Pune (412411) Maharashtra, India.

\section{INTRODUCTION}

Tramadol hydrochloride is a centrally acting synthetic opioid analgesic binding to specific opioid Receptors. It is a nonselective, pure opioid agonist at $\mu$, delta and kappa opioid receptors with a higher affinity for $\mu$ receptors. Tramadol chemically, $\quad(1 \mathrm{R}, 2 \mathrm{R})-2-(($ dimethyl-amino)methyl)-1-(3methoxyphenyl) cyclohexanol hydrochloride (Fig. 1), is a typical opioid which is a centrally acting analgesic used for treating moderate to severe pain1 Tramadol Hydrochloride can be estimated by UV spectrophotometry 1-8, RP-UPLC [912] and GC-MS ${ }^{9}$ alone or in combination with other drugs. Accordingly, the objective of this study was to develop and validate the simple spectrophotometric method for the estimation of tramadol hydrochloride in bulk and tablets as per ICH guidelines. Drug was found to be freely soluble in water which was chosen for solvent proceeding studies.<smiles>CCCCC[C@@](O)(c1cccc(OC)c1)C(C)(C)C</smiles>

\section{MATERIALS AND METHODS}

\section{Chemicals}

Tramadol hydrochloride was a gift sample from Flamingo Pharmaceutical, Taloja, Navi Mumbai, India.. All chemicals and reagents used were of analytical reagent (AR) grade and purchased from Qualigens Fine Chemicals, Mumbai, India.

\section{Instrumentation}

Shimadzu (Kyoto, Japan) model UV- 1800 double beam UVVisible spectrophotometer attached with computer operated software UV probe 2.33 with spectral width of $2 \mathrm{~nm}$, wavelength accuracy of $0.5 \mathrm{~nm}$ and pair of $1 \mathrm{~cm}$ matched quartz cells was used to measure absorbance of the resulting solutions. Analytical balance of make Mettler Toledo (Model JL 1503- C) was used for weighing purpose.

\section{METHOD}

\section{Experimental Work}

\section{A) To check the solubility of Tramadol Hydrochloride}

$25 \mathrm{mg}$ of Tramadol was weighed and solubility of this sample was checked in $25 \mathrm{ml}$ distilled water, methanol, ethanol.

Figure 1: Chemical Structure of Tramadol Hydrochloride. 


\section{B) To identify the $\lambda$ max of Tramadol Hydrochloride:}

Weigh $10 \mathrm{mg}$ of the pure drug and dissolve it in small portion of distilled water and make up the volume upto $10 \mathrm{ml}$ using distilled water to give a standard stock solution of $1000 \mu \mathrm{m} / \mathrm{ml}$. From above solution $2.5 \mathrm{ml}$ of the standard solution was withdrawn in volumetric flask and diluted to 25 $\mathrm{ml}$ to prepare $100 \mathrm{ppm}$ solution. Suitable dilutions were made with distilled water to get standard solutions of concentrations: $5,10,15,20,25 \mu \mathrm{m} / \mathrm{ml}$. Spectrum peak details are shown in Figure2 Spectrum peak pick.
Table 1: Calibration curve of Tramadol Hydrochloride

\begin{tabular}{|l|l|}
\hline Concentration & Absorbance \\
\hline 5 & 0.068 \\
\hline 10 & 0.076 \\
\hline 15 & 0.085 \\
\hline 20 & 0.093 \\
\hline 25 & 0.101 \\
\hline
\end{tabular}

\section{Spectrum Peak Pick Report}

23-04-2019 11:12:48

Data Set: File_190423_110843 - RawData

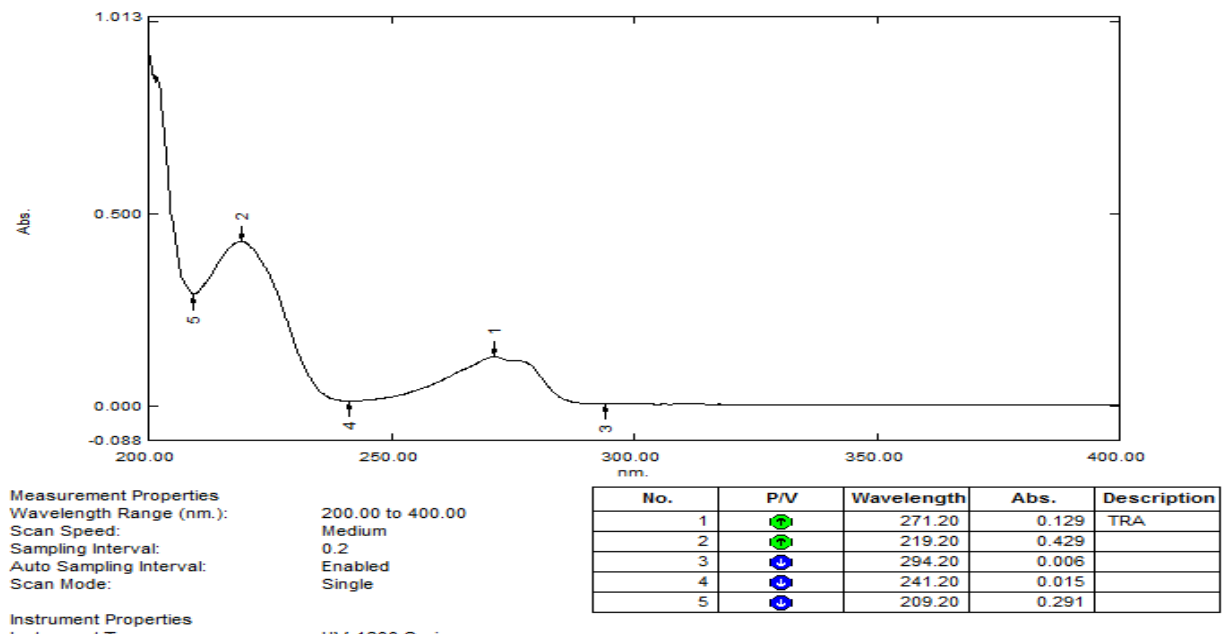
Measuring Mode: $\begin{array}{ll} & 1.0 \mathrm{~nm} \\ \text { Light Source Change Wavelength: } & 340.8 \mathrm{~nm}\end{array}$

Figure 2: Spectrum Peak Pick.

\section{C) Area Under Curve Method:}

In case of AUC (Area under Curve) method is applicable where there is sharp peak or broad spectra are obtained. It involves the calculation of integrated value of absorbance with respect to the wavelength between the two selected wavelengths $\lambda 1$ and $\lambda 2$. Area calculation processing item calculates the area bound by the curve and the horizontal axis. The horizontal axis is selected by the entering the wavelength ranges over which area has to be calculated. This wavelength range is selected on the basis of repeated observation so as to get the linearity between area under curve and concentration. The above mentioned spectrums were used to calculate AUC. Thus, the calibration curve can be constructed by plotting concentration versus AUC.

\section{D) Analytical Method Development and Validation:}

\section{Linearity:}

The linearity of an analytical procedure is the interval between the upper and lower concentration of analyte in the sample. For which demonstrated that the analytical procedure is of linearity. The standard solution of Tramadol $(5,10,15,20$, and $25 \mu \mathrm{m} / \mathrm{ml})$ was pipette out in a separated series of $10 \mathrm{ml}$ volumetric flask. Make up the volume with distilled water and mixed well. The absorbance maxima and area under curve for the solutions was measured at $271 \mathrm{~nm}$ and range of $200-400 \mathrm{~nm}$ for two methods respectively against distilled water as blank. Calibration Curve table of tramadol is shown in Table. 1. Calibration curve of Tramadol.

\section{RESULTS AND DISCUSSION}

\section{A) Calibration Curve for Drug:}

\section{Absorbance maxima method:}

In the Experimental conditions described, the graph obtained for the absorbance maxima for pure drug showed linear relationship (Figure 3). Regression analysis was made for the slope, intercept and and correlation coefficient values. The regression equations of calibration curve were $y$ $=0.0016 \mathrm{x}+0.0603\left(\mathrm{r}^{2}=0.9992\right)$ at $271.00 \mathrm{~nm}$ for absorption maxima the range was found to be $5-25 \mu \mathrm{m} / \mathrm{ml}$ for the UV spectrophotometric analysis. Calibration Curve is shown in Table. 1. Calibration Curve of Tramadol. Calibration curve of Tramadol is shown in Figure. 3. 


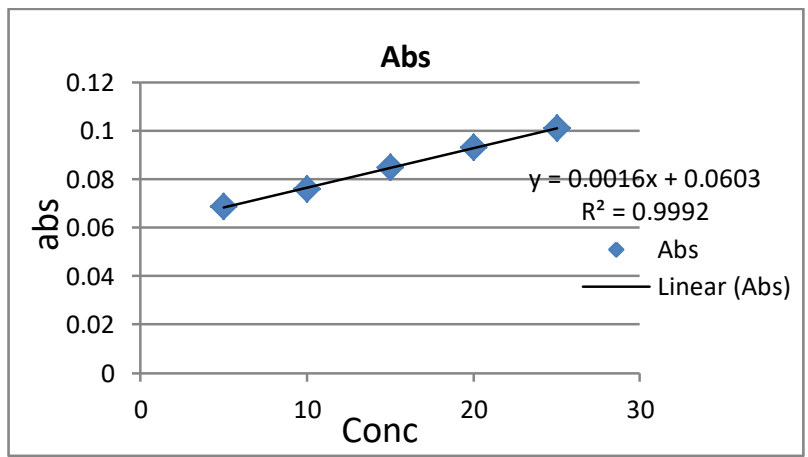

Figure 3: Calibration Curve of Tramadol.

\section{A) Area Under Curve Method :}

In the Experimental conditions described, the graph obtained for the Area Under Curve (AUC) spectra showed linear relationship (Figure 4). Regression analysis was made for the slope, intercept and correlation values. The equation is $\mathrm{y}=0.0016 \mathrm{x}+0.0603\left(\mathrm{r}^{2}=0.9992\right)$ at $200-400 \mathrm{~nm}$ for Area Under Curve spectrophotometry analysis. The range was found to be 5 - $25 \mu \mathrm{m} / \mathrm{ml}$ for the Area Under Curve UV spectrophotometric analysis.

\section{Spectrum Peak Area Report}

Data Set: File_190423_110843 - RawData

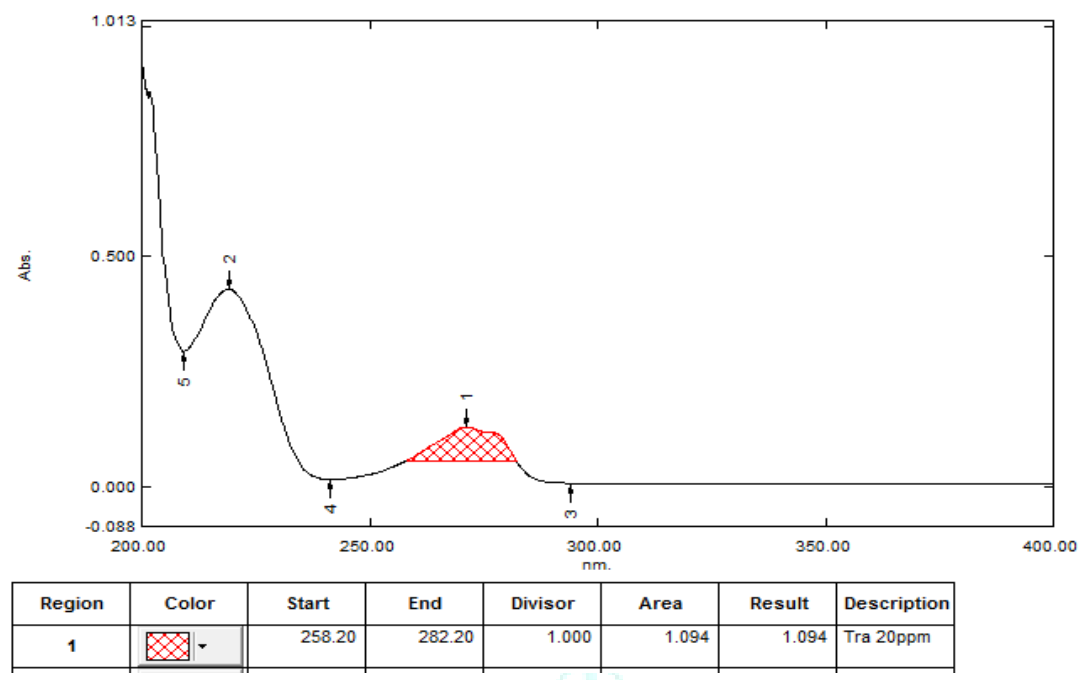

Figure 4: Area Under Curve Of Tramadol.

Table 2: Area Under curve of Tramadol.

\begin{tabular}{|l|l|}
\hline \multicolumn{1}{|c|}{ Parameter } & AUC \\
\hline Wavelength Range $(\mathrm{nm})$ & $200-400$ \\
\hline Concentration Range $(\mu \mathrm{m} / \mathrm{ml})$ & $5-25$ \\
\hline Slope $(\mathrm{m})$ & 0.0016 \\
\hline Intercept $(\mathrm{c})$ & 0.0603 \\
\hline Correlation Coefficient $\left(\mathrm{r}^{2}\right)$ & 0.9992 \\
\hline
\end{tabular}

\section{CONCLUSION}

The simple and economic UV spectrophotometric AUC methods have been developed for the determination of Tramadol. Because of cost-effective and minimal maintenance, the present UV spectrophotometric methods can be preferred at small scale industries and successfully applied and suggested for the qualitative analysis of Tramadol in pharmaceutical formulations for QC, where economy and time are essential and to assure therapeutic efficacy. The results show the UV spectrophotometric method was found to be accurate, precise and sensitive.

\section{ACKNOWLEDGEMENT}

The authors are thankful acknowledge to Dr. S. M. Dhoble Sir Head of Pharmaceutics Department of Vishal Institute of pharmaceutical education and research, Ale, Pune, for constant motivation and encouragement and also Flamingo Pharmaceutical, Taloja, Navi Mumbai, India, for providing Tramadol drug as a gift sample. We would like to thank our principal Dr. Jadhav S. L. for providing us suitable environment for this work.

\section{REFERENCES}

1) Chauhan Sanjay. Development and validation of spectrophotometric method for the estimation of Entacapone in Pharmaceutical formulations. International J. of Chemical Sciences. 2009; 7:349-352

2) https://www.drugbank.ca/drugs/DB00494.

3) International Conference on Harmonization, ICH Harmonized Tripartite Guidelines: Validation of Analytical Procedures, federal Register. 1997:27463.

4) Michael E Swartz, Ira S Krull, Marcel Dekker. Analytical method development and validation, 25-2, 1997.

5) Brand JJ, Colquhoun WP, Gould AH, Perry WLM. (-)-Hyoscine and cyclizine as motion sickness remedies. Br J Pharmac Chemother. 1967; 30:463-469.

6) Beckett, A. H., Stenlake, J. B., Practical Pharmaceutical Chemistry, $4^{\text {th }}$ edition, CBS Publishers and Distributors, New Delhi, 2002; 2:275-295.

7) Christian G D. Analytical chemistry $6^{\text {th }}$ edition, John Willey and Sons, PA, 2003; 1-2:604-620.

8) Saravanan V, Revathi R, Meera N, Method Development and Validation for the Simultaneous Estimation of Lycopene and Ubidecarenone by RP-HPLC in Combined Pharmaceutical Dosage Form. Journal of Drug Delivery and Therapeutics, 2016; $6(5): 46-51$. 
9) Robert A. Nash, et. Al. Pharmaceutical Process Validation, Third Edition, Volume 129, 14, 181.

10) Martindale. The Complete Drug Reference. $32^{32}$ ed. Great Britain: Council of Royal Pharmaceutical Society of Great Britain; 1999.p. 1168.
11) Patel M, Purohit Z, Minal R and Meshram DB, Uv Spectrometric Method for Estimation of Tramadal in Bulk and Tablet Formuletion by Area Under Curve Method, Inter. J. Pharma. Chem. sci. 2014; 3(1). 